\title{
A case review of a Morel-Lavallée lesion with delayed presentation
}

\author{
Ammar Qureshi, MD', Pradeep Monoot, MD²
}

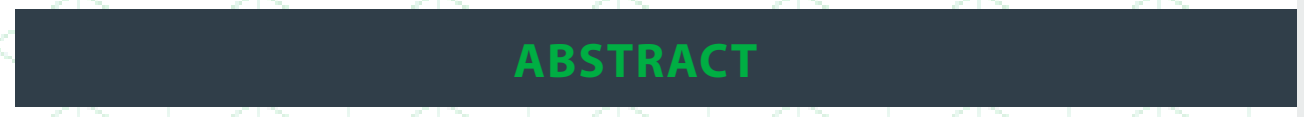

A Morel-Lavallée lesion is a relatively rare post traumatic condition which is sometimes missed at the time of early presentation. It involves a closed internal degloving injury where the subcutaneous tissue is torn away from the underlying fascia, creating a cavity containing hematoma and necrotic fat. It occurs most commonly over the greater trochanter. The lesion can be treated conservatively and surgically. Here we report an unusually delayed presentation of a Morel Lavellee lesion that was treated by incisions, drainage and primary closure.
Author affiliations are listed at the end of this article.

Correspondence to: Ammar Qureshi, MD Marshall University Joan C. Edwards School of Medicine qureshia@marshall.edu

\section{KEYWORDS}

Morel Lavellee lesion, Soft tissue lesion

\section{INTRODUCTION}

The Morel-Lavallée lesion was described by the French Physician Maurice Morel-Lavallée in 1853. ${ }^{1}$ It is caused by a vertical shearing force which causes closed internal degloving where the skin and subcutaneous tissue are separated from the underlying fascia. This separation disrupts the blood vessels and lymphatics which results in the accumulation of blood in a newly formed cavity. The most commonly involved site is over the greater trochanter, while less common sites include pelvis, thigh and knee. ${ }^{2}$

The Morel-Lavallée lesion is associated with a high rate of morbidity and mortality. ${ }^{3}$ The circulation of the soft tissue and skin is compromised. Early complications include recurrence of fluid collection, infections and secondary skin necrosis due to prolonged tissue hypoxia and acidosis. A delayed or untreated condition may worsen the degree of soft tissue necrosis. ${ }^{15}$ Ultimately these lesions may resolve spontaneously; in some cases, however, a pseudocyst may form. MRI is the diagnostic modality of choice. ${ }^{4}$ Delayed diagnosis has been reported in one third cases or more. ${ }^{5}$ Kottmeir et al reported that they are missed up to $44 \%$ of the time. ${ }^{6}$

Treatment involves open debridement and healing by secondary intention ${ }^{7}$. We report a case of a MorelLavallée lesion with delayed presentation involving the distal thigh in a middle aged male, along with management by open debridement and primary closure.

\section{CASE REPORT}

A 45-year-old male presented to the hospital for a swelling which started two weeks ago in distal aspect of the thigh. The swelling was progressively increasing in size, painful, and appeared red to the patient. The patient gave history of a road traffic accident one month ago where he collided with a car while riding a motorcycle. He sustained injury to his chest but did not complain of trauma in his lower limbs. He visited a primary care provider the next day for the chest pain and was advised antiinflammatories and rest. 
He then presented to the senior surgeon (PM) with a swelling on the right thigh that appeared two weeks ago. On local examination, the swelling was seen to be present over the antero-medial and distal aspect of the right thigh. It was spherical, with diffuse margins measuring approximately $6 \times 6 \mathrm{cms}$. The swelling was firm, tender and warm. The knee examination was normal. Neurovascular status was intact.

MRI studies (figures 1-3) showed a large, fluid intensity lesion in the medial aspect of the mid and lower thigh. It appeared hypointense on $\mathrm{T} 1$ and hyperintense on $\mathrm{T} 2 \mathrm{~W}$ images, which suggested a
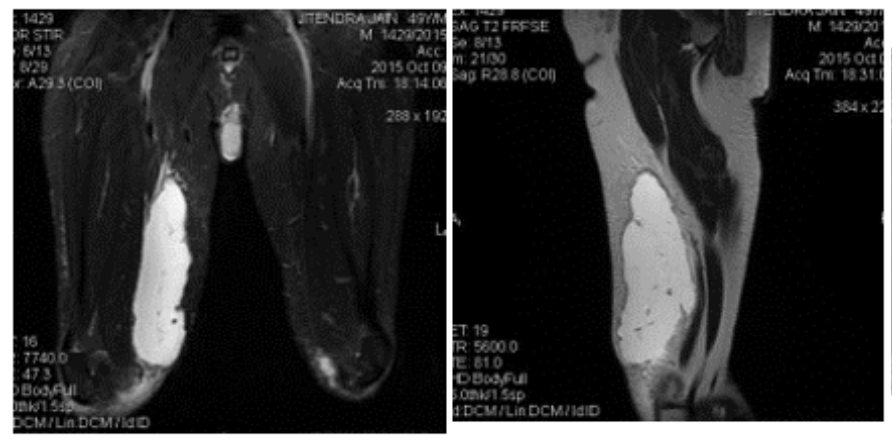

FIGURES 1-3: MRI showing altered signal intensity in the anterior-medial aspect of the right thigh

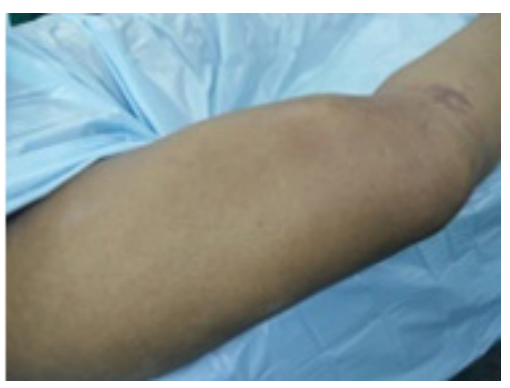

FIGURE 4: Swelling on the Antero medial aspect of right thigh
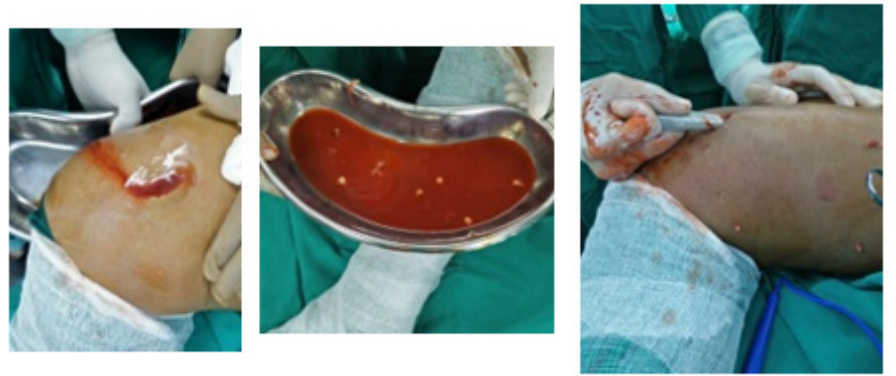

FIGURES 5-7 : Aspiration \& Drainage of Haemorrhagic

Fluid hematoma. There were also focal T1 hyperintensities representing areas of fat necrosis. The margins were irregular, and the lesion was located in the perifascial plane (between the subcutaneous fat and deep fascia). The MRI findings were consistent with those of an internal degloving injury i.e. a Morel-Lavallée lesion.

\section{SURGICAL PROCEDURE}

Informed consent was taken prior to the procedure. The patient was placed in a supine position with a bolster under the ipsilateral buttock (figures 4-8). Regional anaesthesia was used. A 22-gauge

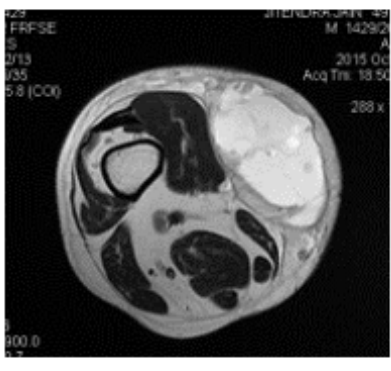
needle with syringe was used to aspirate the contents of the cavity. The tap showed a bloody fluid. A five $\mathrm{cm}$ incision was made directly over the swelling. Approximately $200 \mathrm{ml}$ of a haemorrhagic fluid along with subcutaneous fat was drained out.

Underlying muscles were found to be intact. The entire cavity was curetted and debrided ensuring that all septations were removed. A thorough pulse lavage of the cavity was done. A 12-gauge vacuum drain was placed in the wound. Primary closure of the wound was done using 2-0 nylon sutures and compression dressing was done. The patient was placed on intravenous antibiotics for three days.

Postoperatively, the patient was comfortable and walking from the first day. Postoperative dressing was done on day three. The wound was clean and had no discharge. The drain collection was negligible at the end of three days after which it was removed. The patient was called for a follow up dressing on post op day five. The sutures were removed at the end of two weeks. The wound healed well with primary intention. Follow up was done at six months at which time the patient was rehabilitating well and no recurrent swelling was noted. 


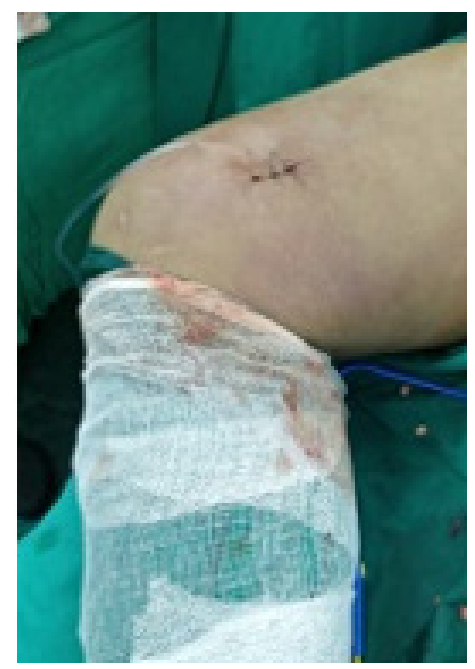

FIGURE 8: Primary Closure of the Wound

\section{DISCUSSION}

An internal degloving injury is usually caused by severe trauma that results in a separation of skin and subcutaneous tissue from the overlying fascia. This results in a cavity filled with blood and necrotic fat. Morel-Lavallée lesions were first described by Maurice Morel-Lavallée in the hip and pelvis. ${ }^{8}$ They are commonly found adjacent to osseous protuberances. ${ }^{7,8}$ The current case is significant in three ways. Firstly the lesion was present in the distal thigh, which is rare as compared to more common sites such as over the greater trochanter. ${ }^{6}$, ${ }^{8-9}$ Studies by Hak et al showed a $30 \%$ of incidence of a Morel-Lavallée lesion at the greater trochanter as compared to a $20 \%$ incidence in the thigh. ${ }^{6,8-9}$

The diagnosis is usually missed, hence delaying treatment, in which case it usually presents with features of soft tissue and skin sloughing and sepsis. The second reason this case is significant is because it clinically appeared to be an abscess with a delayed presentation. However, after an MRI of the lesion, the diagnosis of Morel-Lavallée lesion was confirmed. Finding haemorrhagic fluid on drainage also confirmed this.

In all the studies we have come across, the MorelLavallée lesion presents either immediately or to a maximum of two to three weeks following trauma.
In the current study the lesion presented six weeks after the traumatic incident, proving that a MorelLavallée lesion can be suspected many days after the event. This demonstrated the importance of having a low threshold for ordering an MRI for soft tissue lesions that are suspected to be Morel-Lavallée.

Diagnosis is primarily via history, clinical examination and MRI. Along with determining whether the presentation is acute or chronic, an MRI will help to delineate the stage of the lesion. Mellado and Bencardino proposed an MRI classification system of Morel-Lavallée lesion based on lesion shape, signal and enhancement characteristics and presence or absence of a capsule.

Treatment is primarily surgical. Primary open debridement with closure by secondary intention7 or percutaneous drainage are the surgical methods that are usually done. In the current case, after a thorough debridement the surgeon observed that a primary closure was possible since the margins looked clean. A primary closure would minimise the scarring as compared to secondary healing which is usually done to ensure that further necrosis of the wound does not take place. Conservative options include compression bandaging or sclerotherapy with tetracycline or doxycycline. ${ }^{11-14}$ Sclerotherapy has shown to give successful results ${ }^{7}$.

A retrospective study of 87 Morel-Lavallée lesions demonstrated that lesions with more than $50 \mathrm{ml}$ on drainage are bound to recur but these were percutaneously drained. ${ }^{15}$ We suggest performing a complete open incision and drainage for large collections.

\section{TEACHING POINTS}

A Morel-Lavallée lesion can present late. A clinician has to be aware of such an entity that could mimic an abscess following soft tissue blunt trauma. Moreover, the physician should have a low threshold for ordering an MRI in these cases. Once it is diagnosed, a Morel-Lavallée lesion can be debrided and closed primarily. 


\section{AUTHOR AFFILIATIONS}

1. Marshall University Joan C. Edwards School of Medicine, Huntington, West Virginia

2. S.L. Raheja Hospital, Breach Candy Hospital Trust, Mumbai, India

\section{REFERENCES}

1. Morel-Lavallée M (1863) Decollements traumatiques de la peau et des couches sousjacentes. Arch Gen Med. 1:20-38, 172-200, 300-332.

2. Bonilla-Yoon I, Masih S, Patel DB, White EA, Levine BD, Chow K, Gottsegen CJ, Matcuk GR Jr. The Morel-Lavallée lesion: pathophysiology, clinical presentation, imaging features, and treatment options. Emerg Radiol. 2014;21:35-43.

3. Palacio EP, Guimaraes Di Stasi G, Teixeira Lima HER, Mizobuchi RR, Durigam Junior A, Galbiatti JA. Results from surgical treatment of Morel Lavellee lesions: prospective cohort study. Rev Bras Ortop. 2015;50(2):148-152.

4. Mellado JM, Bencardino JT. Morel-Lavallee lesion: review with emphasis on MR imaging. Magn Reson Imaging ClinNAm. 2005;13:775-782.

5. Powers ML, Halem SF, Sundaram M. Diagnosis: Morel-Lavalee lesion. Orthopedics. 2007;30:3223.

6. Kottmeier S, Wilson SC, Born CT, Hanks GA, lannacone WM, DeLong WG. Surgical management of soft tissue lesions associated with pelvic ring injury. Clin Orthop Relat Res. 1996;( 329):46-53.

7. Tejwani SG, Cohen SB, Bradley JP. Management of Morel-Lavallee lesion of the knee: twenty-seven cases in the national football league. Am J Sports Med. 2007;35(7):1162-1167.

8. Hak DJ, Olson SA, Matta JM. Diagnosis and management of closed internal degloving injuries associated with pelvic and acetabular fractures: the Morel-Lavallee lesion. J Trauma. 1997; 42(6):1046e1051.

9. Letournel E, Judet R. (1993). In: Elson RA, Trans, (Eds.) Fractures of the Acetabulum. (2nd ed., pp 337-397). Berlin, Germany: Springer.

10. Mellado JM, Bencardino JT. Morel-Lavallee lesion: review with emphasis on MR imaging. Magn Reson Imaging Clin N Am. 2005;13(4):775e782.
11. Kumar S, Kumar S. Morel-Lavallée lesion in distal thigh: a case report. Journal of Clinical Orthopaedics and Trauma. 2014;5(3):161-166.

12. Jovanović M, Janjić Z, Vučković N. Giant posttraumatic cyst after closed degloving injury. Arch Oncol. 2007;15(1-2):42-44.

13. Haddad FJ, Younes RN, Gross JL, Deheinzelim D. Pleurodesis in patients with malignant pleural effusions: talc slurry or bleomycin? Results of a prospective randomized trial. World J Surg. 2004;28:749-753.

14. Luria S, Applbaum Y, Weil Y, Liebergall M, Peyser A. Talc sclerodhesis of persistent Morel-Lavallée lesions (posttraumatic pseudocysts): case report of 4 patients. J Orthop Trauma. 2006;20(6):435438.

15. Nickerson TP, Zielinski MD, Jenkins DH, Schiller $\mathrm{HJ}$. The Mayo Clinic experience with Morel Lavallee lesions: establishment of a practice management guideline. J Trauma Acute Care Surg. 2014;76(2):493-497. 